\title{
Editorial: On Time Passing
}

The editor of this Journal must be getting old. The evidence for this lies in his reactions to this issue of the Journal and events around its issue. How things have changed! July 1995 is the World Congress of Behavioural and Cognitive Psychotherapies. Not the kind of thing you would have expected the founding mothers and fathers of behavioural psychotherapy to approve of. However, the founding mothers and fathers are mostly going to be there, and in a spirit of consensus, not of censure. The glue that binds the range of interests that can be found in that Conference, in this Journal, and in the Cognitive and Behavioural Psychotherapy Community as a whole is a strong and abiding belief in a combination of three key factors: an emphasis on empirical evidence, the application of the scientist practitioner approach, and the abiding clinical importance of offering understanding to the people we try to help. So perhaps things have not changed quite so much. All of these elements can be found in Wolpe's 1958 Psychotherapy by Reciprocal Inbibition.

On behalf of the BABCP and this Journal I wish the Conference every success and would like to express the appreciation of the Behavioural and Cognitive Psychotherapy Communities to David Clark, Chair of the Cognitive Scientific Committee, Lars-Goran Öst, Chair of the Behavioural Scientific Committee and to Irene Oestrich, the Congress Organizer and the person whose vision has held the whole thing together.

Oh, but how things have changed! In 1984 I published a paper on intrusive thoughts which was a replication of Rachman and de Silva's (1978) work on normal intrusive thoughts, considering their relationship to the psychopathology of obsessional problems. Here, eleven years later, we are seeing a special issue of Bebavioural and Cognitive Psychotherapy devoted to the topic of intrusive cognitions, including pages on PTSD, psychotic problems-but what a relief, obsessional problems are still there and, what is more, you can see the influence of the work by Jack Rachman and Joe Wolpe. So maybe things have not changed so much after all!

So, I would like to thank Adrian Wells for acting as guest editor for this special issue, and for showing that I am not really so very old.

PaUl Salkovskis Editor, Behavioural and Cognitive Psychotherapy 